Pacific Journal of Mathematics

BICONTINUOUS REORDERED TOPOLOGICAL SPACES 


\section{BICONTINUOUS PREORDERED TOPOLOGICAL SPACES}

\section{S. D. MCCARTAN}

In this paper, preordered topological spaces obeying two natural conditions, known as bicontinuous preordered spaces, are studied. The relationship between the topology of such a space and two associated convex topologies is examined.

Let $(X, \mathscr{T}, \leqq)$ be a preordered topological space (that is, $X$ is a set endowed with both a topology $\mathscr{T}$ and a preorder $\leqq$ and is usually denoted by $(X, \mathscr{T}))$. For each $x \in X$ and $A \subseteq X$,

$$
\begin{aligned}
{[x, \rightarrow]=\{y \in X: x \leqq y\}, } & {[\leftarrow, x]=\{y \in X: y \leqq x\}, } \\
i(A)=\bigcup\{[x, \rightarrow]: x \in A\}, & d(A)=\bigcup\{[\leftarrow, x]: x \in A\}
\end{aligned}
$$

and $A$ is increasing (decreasing, convex) in $X$ if and only if $A=i(A)$ $(A=d(A), A=i(A) \bigcap d(A)) . \quad \bar{A}$ denotes the $\mathscr{T}$-closure of $A$ in $X$. $(X, \mathscr{T})$ is said to be continuous (anti-continuous) if and only if for each $\mathscr{T}$-open subset $G(\mathscr{T}$-closed subset $F) i(G)$ and $d(G)$ are $\mathscr{T}$-open $(i(F)$ and $d(F)$ are $\mathscr{T}$-closed). $(X, \mathscr{T})$ is said to be bicontinuous if and only if it is both continuous and anti-continuous. The topology $\mathscr{T}$ (or often it is said the preordered space $(X, \mathscr{T})$ ) is locally convex if and only if the set of convex $\mathscr{T}$-neighbourhoods of each member of $X$ is a base for the $\mathscr{T}$-neighourhood system of the member, weakly convex if and only if the set of convex $\mathscr{T}$-open subsets is a base for $\mathscr{T}$, almost convex if and only if the set of convex $\mathscr{T}$-closed subsets is a subbase for the family of $\mathscr{T}$-closed susets, and convex if and only if the set of $\mathscr{T}$-open subsets which are either increasing or decreasing is a subbase for $\mathscr{T}$. It is evident that for a preordered space, convexity implies weak convexity which, in turn, implies local convexity and also, convexity implies almost convexity.

Let $\mathscr{F}_{d}$ be the collection of all subsets of $X$ of the form $i(F)$, $d(F)$, where $F$ is a $\mathscr{T}$-closed subset of $X$ and let $\mathscr{G}_{c}$ be the collection of all subsets of $X$ of the form $i(G), d(G)$, where $G$ is a $\mathscr{T}$ : open subset of $X$. Then $\mathscr{F}_{d}$ and $\mathscr{G}_{c}$ form, respectively, a subbase for the closed sets and a subbase, for convex topologies $\mathscr{T}_{d}$ and $\mathscr{T}_{c}$ which are known as the $\mathscr{T}$-associated convex topologies for $X$. The topology $\mathscr{T}_{c}$ was introduced by Green [1] and some of his results are quoted here without proof. It is of interest to learn that even when $(X, \mathscr{T})$ is a convex preordered space, neither $\mathscr{T}=\mathscr{T}_{d}, \mathscr{T}=\mathscr{T}_{c}$ nor $\mathscr{T}_{d}=\mathscr{T}_{c}$ need be true (see Examples 1,2).

THEOREM 1. (i) $(X, \mathscr{T})$ is anti-continuous if and only if 
$\overline{i(A)} \leqq i(\bar{A})$ and $\overline{d(A)} \subseteq d(\bar{A})$ for every $A \subseteq X$.

(ii) $(X, \mathscr{T})$ is continuous if and only if $i(\bar{A}) \subseteq \overline{i(A)}$ and $d(\bar{A}) \leqq \overline{d(A)}$ for every $A \subseteq X$.

(iii) $(X, \mathscr{T})$ is bicontinuous if and only if $i(\bar{A})=\overline{i(A)}$ and $d(\bar{A})=\overline{d(A)}$ for every $A \subseteq X$.

Proof. (i) Let $(X, \mathscr{T})$ be anti-continuous; then, for every $A \subseteq X, i(\bar{A})$ contains $i(A)$ and is $\mathscr{T}$-closed, so that $\overline{i(A)} \cong i(\bar{A})$. Dually, $\overline{d(A)} \subseteq d(\bar{A})$.

Conversely, let $F \leqq X$ be $\mathscr{T}$-closed, then $F=\bar{F}$ and

$$
\overline{i(F)} \subseteq i(\bar{F})=i(F)
$$

so that $i(F)$ is $\mathscr{T}$-closed. Dually, $d(F)$ is $\mathscr{T}$-closed.

(ii) Let $(X, \mathscr{T})$ be continuous; then, for every $A \subseteq X$, $X-d(X-\overline{i(A)})$ is $\mathscr{T}$-closed, clearly increasing and contains $A$ so that

$$
\overline{i(A)} \subseteq X-d(X-\overline{i(A)}) \text {. }
$$

On the other hand, $X-\overline{i(A)} \subseteq d(X-\overline{i(A))}$ implies

$$
X-d(X-\overline{i(A)} \subseteq \overline{i(A)},
$$

and thus

$$
\overline{i(A)}=X-d(X-\overline{i(A)}) \text {. }
$$

Hence, $i(\bar{A}) \subseteq \overline{i(A)}$. Dually, $d(\bar{A}) \subseteq \overline{d(A)}$.

Conversely, let $i(\bar{A}) \subseteq \overline{i(A)}$ and $d(\bar{A}) \leqq \overline{d(A)}$ for every $A \subseteq X$ and let $G \leqq X$ be $\mathscr{T}$-open. Then $X-G$ is $\mathscr{T}$-closed and $\overline{X-i(G)} \subseteq X-G$ so that $G \subseteq X-\overline{(X-i(G)})$. By hypothesis,

$$
d \overline{(X-i(G))} \cong \overline{d(X-i(G)}=\overline{(X-i(G))}
$$

so that $\overline{X-i(G)}$ is decreasing. Thus $i(G) \subseteq X-\overline{(X-i(G)})$. On the other hand, it is clear that $X-i(G) \subseteq \overline{X-i(G)}$ and hence

$$
X-(\overline{X-i(G)}) \leqq i(G) \text {. }
$$

Consequently, $i(G)=X-(\overline{X-i(G)})$ is $\mathscr{T}$-open. Dually, $d(G)$ is $\mathscr{T}$-open.

(iii) This is immediate from ( $i$ ) and (ii) above.

The following examples show that the "continuity" and "anti-continuity" concepts for a preordered space are logically independent.

EXAMPLE 1. Let $X=Y \bigcup\{w\}$, where $Y$ is the subset $\{(x, x): 0 \leqq x \leqq 1\}$ and $w$ is the element $(0,1)$ of the real plane. $X$ 
is (partially) ordered by agreeing that $(a, b) \leqq(c, d)$ if and only if $a \leqq c$ and $b \leqq d$ in the real line. Let $\mathscr{C}$ denote the usual metric topology for $X$. Let $A=Y-\{(0,0)\}$, then $A$ is increasing in $X$, $\bar{A}=Y, w \in i(\bar{A})=i(Y)=X$, and $w \notin \overline{i(A)}=\bar{A}=Y$. By Theorem 1 (ii), $(X, \mathscr{C})$ is not continuous.

However, it is evident that $(X, \mathscr{C})$ is a compact space and, since $\mathscr{C}=\mathscr{J}$ the well-known interval topology for $X$, it follows from [2, Theorem 2] that $(X, \mathscr{C})$ is a $H$-ordered space so that, by [5, Proposition 4, p. 44], $(X, \mathscr{C})$ is anti-continuous.

Example 2. Let $X=A \cup B \cup C \cup\{w\}$, where $A=\left\{a_{n}: n \geqslant 2\right\}$, $B=\left\{b_{n}: n \geqslant 2\right\}, C=\left\{c_{n}: n \geqslant 2\right\}$ and where $a_{n}, b_{n}, c_{n}, w$ are the elements $(1 / n, 1-1 / n),(1 / n, 0),(0,1-1 / n),(0,1)$ respectively of the real plane for each $n \geqq 2$. $X$ is (partially) ordered as in Example 1 above. Let $\mathscr{C}$ denote the usual metric topology for $X$. It is clear that the sequences $\left\{a_{n}, n \geqslant 2\right\}, \quad\left\{c_{n}, n \geqslant 2\right\} \mathscr{C}$-converge to $w$ in $X$ and that each singleton subset of $X$, with the exception of $\{w\}$, is $\mathscr{C}$-open.

Let $E$ be an increasing subset of $X$. Then, either $\bar{E}=E$ or $\bar{E}=$ $E \cup\{w\}$, so that $\bar{E}$ is increasing in $X$. If $E$ is a decreasing subset of $X$ and $w \in E$, then $E$ is $\mathscr{C}$-closed and $\bar{E}=E$. If $w \notin E$, there exist two possibilities:

(i) $E \cap C$ is finite. In this case, since $E$ is decreasing in $X$, $E \cap A$ is also finite. Assuming that it is nonempty, $E \cap B$ is decreasing in $X$ since both $E$ and $B$ are decreasing in $X$, and $E \cap B$ is linear and hence $E \cap B=\left[\leftarrow, b_{m}\right]$, where $m$ is the least integer $n \geqslant 2$ such that $b_{n} \in E \cap B$. Then,

$$
E=E \cap(A \cup B \cup C)=(E \cap A) \cup(E \cap B) \cup(E \cap C)
$$

is $\mathscr{C}$-closed and $\bar{E}=E$.

(ii) $E \cap C$ is infinite. In this case $C \subseteq E$ (otherwise there exists $c \in C \cap(X-E)$ so that, since $E$ is decreasing in $X, E \cap[c, \rightarrow]$ is empty which implies that $E \cap C=E \cap\{[c, \rightarrow] \cup[\leftarrow, c]\}=E \cap[\leftarrow, c]$ is finite). The sequence $\left\{c_{n}\right\} \mathscr{C}$-converges to $w$ so that $E$ is not $\mathscr{C}$-closed but $\bar{E}=E \cup\{w\}$. Since $[\leftarrow, w]=C \cup\{w\} \subseteq E \cup\{w\}, \bar{E}$ is decreasing in $X$.

Consequently, it follows directly from [1, Lemma 1] that $(X, \mathscr{C})$ is continuous.

However, although $B \equiv\left[\leftarrow, b_{2}\right]$ is $\mathscr{C l}$-closed, $i(B)=A \cup B$ is not $\mathscr{A l}$-closed since the sequence $\left\{a_{n}\right\} \mathscr{C}$-converges to $w$. It follows that $(X, \mathscr{C l})$ is not anti-continuous.

THEOREM 2. Let $(X, \mathscr{T})$ be a preordered space.

(i) $\mathscr{T}_{d} \subseteq \mathscr{T}$ if and only if $(X, \mathscr{T})$ is an anti-continuous space. 
In this case, $\left(X, \mathscr{T}_{d}\right)$ is also anti-continuous.

(ii) If $\mathscr{S}$ is an almost convex topology for $X$, with respect to the preorder on $X$, and if $\mathscr{S} \subseteq \mathscr{T}$, then $\mathscr{S} \subseteq \mathscr{T}_{d}$.

In particular, if $\mathscr{T}$ is almost convex, $\mathscr{T} \cong \mathscr{T}_{d}$.

Proof. (i) By definition, $(X, \mathscr{T})$ is anti-continuous if and only if each member of $\mathscr{F}_{d}$ is $\mathscr{T}$-closed; hence if and only if $\mathscr{T}_{d} \subseteq \mathscr{T}$.

If $\mathscr{T}_{d} \subseteq \mathscr{T}$ for $X$ and if $F \cong X$ is $\mathscr{T}_{d}$-closed, then $F$ is $\mathscr{T}$ closed which implies, in particular, that $i(F)$ and $d(F)$ are $\mathscr{T}_{d}$-closed and hence $\left(X, \mathscr{T}_{d}\right)$ is anti-continuous.

(ii) Let $F$ be $\mathscr{S}$-closed in $X$. Since $\mathscr{S}$ is almost convex there is no loss in generality in assuming that $F$ is convex in $X$. Then, by hypothesis, $F$ is $\mathscr{T}$-closed and $F=i(F) \cap d(F)$ is $\mathscr{T}_{d}$-closed. Thus $\mathscr{S} \cong \mathscr{T}_{d}$ for $X$.

Corollary. Let $(X, \mathscr{T})$ be a preordered space. Then, if $\mathscr{T}_{d} \subseteq \mathscr{T}$, $\mathscr{T}_{d}$ is the maximum of all almost convex topologies on $X$ which are weaker than $\mathscr{T}$. The following statements are equivalent:

(i) $(X, \mathscr{T})$ is a convex anti-continuous preordered space.

(ii) $(X, \mathscr{T})$ is an almost convex anti-continuous preordered space.

(iii) $\mathscr{T}=\mathscr{T}_{d}$.

THeOREM 3 [1]. Let $(X, \mathscr{T})$ be a preordered space.

(i) $\mathscr{T}_{c} \subseteq \mathscr{T}$ if and only if $(X, \mathscr{T})$ is a continuous space. In this case, $\left(X, \mathscr{T}_{c}\right)$ is also a continuous space.

(ii) If $\mathscr{S}$ is a locally convex topology for $X$, with respect to the preorder on $X$, and if $\mathscr{S} \subseteq \mathscr{T}$, then $\mathscr{S} \subseteq \mathscr{T}_{\circ}$.

In particular, if $\mathscr{T}$ is locally convex, $\mathscr{T} \cong \mathscr{T}_{c}$.

Proof. Arguments, analogous to these in the proof of Theorem 2, will suffice.

Corollary 1. Let $(X, \mathscr{T})$ be a preordered space. Then if $\mathscr{T}_{c} \subseteq \mathscr{T}$, $\mathscr{T}_{c}$ is the maximum of all locally convex topologies on $X$ which are weaker than $\mathscr{T}$. The following statements are equivalent:

(i) $(X, \mathscr{T})$ is a convex continuous preordered space.

(ii) $(X, \mathscr{T})$ is weakly convex continuous preordered space.

(iii) $(X, \mathscr{T})$ is a locally convex continuous preordered space.

(iv) $\mathscr{T}=\mathscr{T}_{c}$.

CoRollary 2. $(X, \mathscr{T})$ is a convex bicontinuous preordered space if and only if $\mathscr{T}_{d}=\mathscr{T}=\mathscr{T}_{c}$.

Example 3. Let $(X, \mathscr{C})$ be the ordered space of Example 1. 
Since $\mathscr{M}=\mathscr{F}, \mathscr{C}$ is evidently a convex topology for $X$. Therefore, $\mathscr{A}=\mathscr{M}_{d}$ by Theorem 2, Corollary; however, by Theorem 3 and Example 1, $\mathscr{L} \subset \mathscr{A}_{c}$.

Example 4. Let $(X, \mathscr{C})$ be the ordered space of Example 2. Again, it is evident that $\mathscr{C}=\mathscr{F}$ for $X$ and it follows, by Theorem 2, Theorem 3, Corollary 1 and Example 2, that $\mathscr{H}_{c}=\mathscr{L}_{C} \subset \mathscr{M}_{d}$.

More generally, it may be seen from Theorem 2, Corollary and Theorem 3, Corollary 1, that for a preordered space $(X, \mathscr{T})$, if $\mathscr{T}=\mathscr{T}_{d}\left(\mathscr{T}=\mathscr{T}_{c}\right)$ then $\mathscr{T} \cong \mathscr{T}_{c}\left(\mathscr{T} \cong \mathscr{T}_{d}\right)$. Also from Theorem 2 (ii) and 3 (ii), it follows that $\mathscr{T}_{d} \subset \mathscr{T}\left(\mathscr{T}_{c} \subset \mathscr{T}\right)$ implies $\mathscr{T}_{d} \subseteq \mathscr{T}_{c}$ $\left(\mathscr{T}_{c} \subseteq \mathscr{T}_{d}\right)$. From these considerations and Theorems $2(\mathrm{i})$ and 3 (i), the following result may be deduced:

Theorem 4. $(X, \mathscr{T})$ is a bicontinuous preordered space if and only if $\mathscr{T}_{c}=\mathscr{T}_{d} \subseteq \mathscr{S}$.

EXAMPLE 5. Let $N$ denote the set of integers with the usual magnitude order and let $\mathscr{C}$ be the cofinite topology for $N$. If $U \subseteq N$ is $\mathscr{C}$-open, then $i(U)=N=d(U)$ and $(N, \mathscr{C})$ is a continuous space. However, if $n \in N$, neither $i(\{n\})=[n, \rightarrow]$ nor $d([n])=[\leftarrow, n]$ is $\mathscr{C}$ closed and $(N, \mathscr{C})$ is not anti-continuous. Since the only increasing or decreasing $\mathscr{C}$-open subsets of $N$ are $N$ and the empty set, it follows that $(N, \mathscr{C})$ is not a convex ordered space and hence not locally convex by Corollary 1, although it is evidently almost convex.

When it is remarked that $\mathscr{C}_{c}, \mathscr{C}_{d}$ are the trivial and discrete topologies respectively, for $N$, it becomes clear that $\mathscr{C}_{c} \subset \mathscr{C}=\mathscr{C}_{d}$.

2. Let $(X, \mathscr{T})$ be a preordered space and let $A \subseteq X$. Then $A$

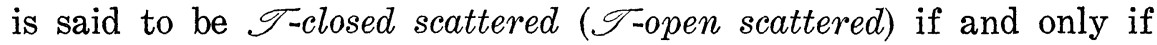

$$
\begin{array}{rll}
i(F) \cap A \subseteq i(F \cap A) & \text { and } & d(F) \cap A \subseteq d(F \cap A) \\
(i(U) \cap A \subseteq i(U \cap A) & \text { and } & d(U) \cap A \subseteq d(U \cap A))
\end{array}
$$

for each $\mathscr{T}$-closed $F(\mathscr{T}$-open $U) \leqq X$ such that $F \cap A(U \cap A)$ is nonempty.

Theorem 5. (i ) If $A$ is $\mathscr{T}$-closed scattered, then $\left(\mathscr{T}_{A}\right)_{d} \subseteq\left(\mathscr{T}_{d}\right)_{A}$.

(ii) If $(X, \mathscr{T})$ is anti-continuous, then, $\left(\mathscr{T}_{d}\right)_{A} \subseteq\left(\mathscr{T}_{A}\right)_{d}$.

(iii) If $(X, \mathscr{T})$ is almost convex and anti-continuous, then

$$
\mathscr{T}_{A}=\left(\mathscr{T}_{d}\right)_{A} \subseteq\left(\mathscr{T}_{A}\right)_{d}
$$

Proof. (i) Let $F \cong A$ be $\mathscr{T}_{A}$-closed, then there exists a $\mathscr{T}$ - 
closed $F^{*}$ with $F=F^{*} \cap A$. Thus

$$
i(F) \cap A=i\left(F^{*} \cap A\right) \cap A=i\left(F^{*}\right) \cap A
$$

is $\left(\mathscr{T}_{d}\right)_{A}$-closed. Dually, $d(F) \cap A$ is $\left(\mathscr{T}_{d}\right)_{A}$-closed.

(ii) If $F$ is $\mathscr{T}$-closed in $X$, then, by hypothesis, $i(F), d(F)$ are $\mathscr{T}$-closed so that $i(F) \cap A, d(F) \cap A$ are $\mathscr{I}_{A}$-closed (as well as, respectively, increasing and decreasing in $A$ ) so that $\left(\mathscr{T}_{d}\right)_{A} \subseteq\left(\mathscr{T}_{A}\right)_{d}$.

(iii) This is immediate from (ii) above and Theorem 2, Corollary.

Theorem 6. [1]. (i) If $A$ is $\mathscr{T}$-open scattered, then $\left(\mathscr{T}_{A}\right)_{c} \subseteq\left(\mathscr{T}_{c}\right)_{A}$.

(ii) If $(X, \mathscr{T})$ is continuous, then $\left(\mathscr{T}_{c}\right)_{A} \subseteq\left(\mathscr{T}_{A}\right)_{c}$.

(iii) If $(X, \mathscr{T})$ is locally convex and continuous, then $\mathscr{I}_{A}=$ $\left(\mathscr{T}_{c}\right)_{A} \subseteq\left(\mathscr{T}_{A}\right)_{c}$

Proof. Arguments analogous to those adopted in the proof of Theorem 5 will suffice.

Corollary. (i) If $(X, \mathscr{T})$ is bicontinuous, then

$$
\left(\mathscr{T}_{c}\right)_{A}=\left(\mathscr{T}_{d}\right)_{A} \subseteq\left(\mathscr{T}_{A}\right)_{d},\left(\mathscr{T}_{d}\right)_{A}=\left(\mathscr{T}_{c}\right)_{A} \subseteq\left(\mathscr{T}_{A}\right)_{c}
$$

and

$$
\left(\mathscr{T}_{d}\right)_{A}=\left(\mathscr{T}_{c}\right)_{A} \subseteq \mathscr{T}_{A}
$$

(ii) If $(X, \mathscr{T})$ is convex and bicontinuous, then

$$
\left(\mathscr{T}_{c}\right)_{A}=\left(\mathscr{T}_{d}\right)_{A}=\mathscr{T}_{A} \leqq\left(\mathscr{T}_{A}\right)_{d} \quad \text { and } \quad\left(\mathscr{T}_{c}\right)_{A}=\left(\mathscr{T}_{d}\right)_{A}=\mathscr{T}_{A} \leqq\left(\mathscr{T}_{A}\right)_{c} .
$$

Proof. (i) This is immediate by Theorem 4, 5 and 6 .

(ii) This is immediate, by Theorem 3, Corollary 2 and Theorems 5,6 .

ExAmple 6 . Let $(N, \mathscr{C})$ be the ordered space of Example 5 and let $A$ be a finite subset of $N$ containing at least two distinct members. It is evident that $A$ is neither $\mathscr{C}$-open scattered nor $\mathscr{C}$-closed scattered and that $\left(A, \mathscr{C}_{A}\right)$ is a discrete space so that $\left(\mathscr{C}_{A}\right)_{c}=\mathscr{C}_{A}$, yet $\left(\mathscr{C}_{c}\right)_{A} \subset\left(\mathscr{C}_{A}\right)_{c}$ for $\left(A,\left(\mathscr{C}_{c}\right)_{A}\right)$ is a trivial space. Similarly, $\left(\mathscr{C}_{A}\right)_{d}=$ $\mathscr{C}_{A}$ and, in fact, $\left(\mathscr{C}_{A}\right)_{d}=\left(\mathscr{C}_{d}\right)_{A}=\mathscr{C}_{A}$ for, if $x \in A$,

$$
\{x\}=[x, \rightarrow] \cap[\leftarrow, x] \cap A=\{i(\{x\}) \cap d(\{x\})\} \cap A
$$

is $\left(\mathscr{C}_{d}\right)_{A}$-closed and $\left(A,\left(\mathscr{C}_{d}\right)_{A}\right)$ is a discrete space.

Let $a<b<c$ in $N$, then $B=N-\{a\}$ is $\mathscr{C}$-open scattered but not $\mathscr{C}$-closed scattered. For, $F=\{a, c\}$ is $\mathscr{C}$-closed in $N$ but 


$$
i(F \cap B) \cap B=[c, \rightarrow] \subset[a+1, \rightarrow]=i(F) \cap B .
$$

It is also clear that $\left(\mathscr{C}_{B}\right)_{c}=\left(\mathscr{C}_{c}\right)_{B} \subset \mathscr{C}_{B}$, since $\mathscr{C}_{B}$ is the cofinite topology for $B$ while $\left(\mathscr{C}_{B}\right)_{c}=\left(\mathscr{C}_{c}\right)_{B}$ is the trivial topology for $B$. Also, since $\left(\mathscr{C}_{B}\right)_{d}=\left(\mathscr{C}_{d}\right)_{B}$ is the discrete topology for $B$,

$$
\mathscr{C}_{B} \subset\left(\mathscr{C}_{B}\right)_{d}=\left(\mathscr{C}_{d}\right)_{B} \text {. }
$$

Finally, an abstract topological space, when viewed as an ordered topological space with the trivial order, is clearly bicontinuous. Consequently, in attempting to generalize classical topological results in ordered spaces, it seems appropriate to work with bicontinuous ordered spaces. Some support to this observation is provided in [4]. For example, if $(X, \mathscr{T})$ is a bicontinuous $T_{1}$-space, then $\left(X, \mathscr{T}_{d}\right)$ is a $T_{1}$ ordered space (see [3]) and, by Theorem 2 above, $\mathscr{T}_{d} \subseteq \mathscr{T}$ for $X$ so that $(X, \mathscr{T})$ is a $T_{1}$-ordered space.

\section{REFERENCES}

1. M. D. Green, locally convex topology on a preordered space, Pacific J. Math., 26 (1968), 487-491.

2. S. D. McCartan, On the H-ordered interval topology, J. London Math. Soc., 43 (1968), 517-520.

3. - Separation axioms for topological ordered spaces, Proc. Camb. Phil. Soc., 64 (1968), 965-973.

4. - Topics in ordered topological spaces, Thesis, Queen's University, Belfast, 1969.

5. L. Nachbin, Topology and order, Van Nostrand, 1965.

Received June 8, 1970, and in revised form September 26, 1970.

NORTHERN ILLINOIS UNIVERSITY

AND

Queen's University, Belfast, N. Ireland. 



\section{PACIFIC JOURNAL OF MATHEMATICS}

\section{EDITORS}

\author{
H. SAMELSON \\ Stanford University \\ Stanford, California 94305 \\ C. R. HовBY \\ University of Washington \\ Seattle, Washington 98105
}

J. DUGUndis

Department of Mathematics

University of Southern California

Los Angeles, California 90007

RICHARD ARENS

University of California

Los Angeles, California 90024

\section{ASSOCIATE EDITORS}
E. F. BeCKenbaCH
B. H. NeUmanN
F. WOLF
K. YoshidA

\section{SUPPORTING INSTITUTIONS}

\author{
UNIVERSITY OF BRITISH COLUMBIA \\ CALIFORNIA INSTITUTE OF TECHNOLOGY \\ UNIVERSITY OF CALIFORNIA \\ MONTANA STATE UNIVERSITY \\ UNIVERSITY OF NEVADA \\ NEW MEXICO STATE UNIVERSITY \\ OREGON STATE UNIVERSITY \\ UNIVERSITY OF OREGON \\ OSAKA UNIVERSITY \\ UNIVERSITY OF SOUTHERN CALIFORNIA
}

\author{
STANFORD UNIVERSITY \\ UNIVERSITY OF TOKYO \\ UNIVERSITY OF UTAH \\ WASHINGTON STATE UNIVERSITY \\ UNIVERSITY OF WASHINGTON

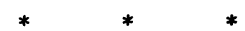 \\ AMERICAN MATHEMATICAL SOCIETY \\ CHEVRON RESEARCH CORPORATION \\ NAVAL WEAPONS CENTER
}

The Supporting Institutions listed above contribute to the cost of publication of this Journal, but they are not owners or publishers and have no responsibility for its content or policies.

Mathematical papers intended for publication in the Pacific Journal of Mathematics should be in typed form or offset-reproduced, (not dittoed), double spaced with large margins. Underline Greek letters in red, German in green, and script in blue. The first paragraph or two must be capable of being used separately as a synopsis of the entire paper. The editorial "we" must not be used in the synopsis, and items of the bibliography should not be cited there unless absolutely necessary, in which case they must be identified by author and Journal, rather than by item number. Manuscripts, in duplicate if possible, may be sent to any one of the four editors. Please classify according to the scheme of Math. Rev. Index to Vol. 39. All other communications to the editors should be addressed to the managing editor, Richard Arens, University of California, Los Angeles, California, 90024.

50 reprints are provided free for each article; additional copies may be obtained at cost in multiples of 50 .

The Pacific Journal of Mathematics is published monthly. Effective with Volume 16 the price per volume (3 numbers) is $\$ 8.00$; single issues, $\$ 3.00$. Special price for current issues to individual faculty members of supporting institutions and to individual members of the American Mathematical Society: $\$ 4.00$ per volume; single issues $\$ 1.50$. Back numbers are available.

Subscriptions, orders for back numbers, and changes of address should be sent to Pacific Journal of Mathematics, 103 Highland Boulevard, Berkeley, California, 94708.

PUBLISHED BY PACIFIC JOURNAL OF MATHEMATICS, A NON-PROFIT CORPORATION

Printed at Kokusai Bunken Insatsusha (International Academic Printing Co., Ltd.), 7-17, Fujimi 2-chome, Chiyoda-ku, Tokyo, Japan. 


\section{Pacific Journal of Mathematics}

Vol. 38, No. $2 \quad$ April, 1971

Richard Davis Anderson and Thomas Ashland Chapman, Extending

homeomorphisms to Hilbert cube manifolds .................. 281

Nguyen Huu Anh, Restriction of the principal series of $\operatorname{SL}(n, \mathbf{C})$ to some

reductive subgroups................................ 295

David W. Boyd, Indices for the Orlicz spaces . . . . . . . . . . . . 315

William Garfield Bridges, The polynomial of a non-regular digraph ...... 325

Billie Chandler Carlson, Robert K. Meany and Stuart Alan Nelson, Mixed

arithmetic and geometric means........................ 343

H. A. Çelik, Commutative associative rings and anti-flexible rings ...... 351

Hsin Chu, On the structure of almost periodic transformation groups ...... 359

David Allyn Drake, The translation groups of n-uniform translation

Hjelmslev planes ................................ 365

Michael Benton Freeman, The polynomial hull of a thin two-manifold . . . . 377

Anthony Alfred Gioia and Donald Goldsmith, Convolutions of arithmetic

functions over cohesive basic sequences .................... 391

Leslie C. Glaser, A proof of the most general polyhedral Schoenflies

conjecture possible ................................

Thomas Lee Hayden and Ted Joe Suffridge, Biholomorphic maps in Hilbert

space have a fixed point ................................ 419

Roger Alan Horn, Schlicht mappings and infinitely divisible kernels ...... 423

Norman Ray Howes, On completeness ...................... 431

Hideo Imai, Sario potentials on Riemannian spaces................ 441

A. A. Iskander, Subalgebra systems of powers of partial universal

algebras.

Barry E. Johnson, Norms of derivations of $\mathscr{L}(\mathrm{X})$.

David Clifford Kay and Eugene W. Womble, Axiomatic convexity theory and relationships between the Carathéodory, Helly, and Radon numbers

Constantine G. Lascarides, A study of certain sequence spaces of Maddox

and a generalization of a theorem of Iyer .............

C. N. Linden, On Blaschke products of restricted growth .

John S. Lowndes, Some triple integral equations ................. 515

Declan McCartan, Bicontinuous preordered topological spaces ......... 523

S. Moedomo and J. Jerry Uhl, Jr., Radon-Nikodým theorems for the Bochner and Pettis integrals ...

Calvin Cooper Moore and Joseph Albert Wolf, Totally real representations

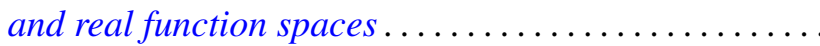

Reese Trego Prosser, A form of the moment problem for Lie groups. ... 